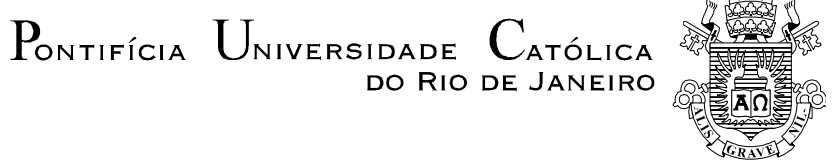

Tanya Linda Rothgiesser

Cidadania Digital: uma proposta de educação complementar para a inclusão digital e o combate às desigualdades sociais no Brasil contemporâneo - 0 caso CDI

Dissertação apresentada ao Programa de Pósgraduação em Ciências Sociais da PUC-Rio como requisito parcial para obtenção do título de Mestre em Ciências Sociais.

Orientador: Prof. Eduardo de Vasconcelos Raposo

Rio de Janeiro Agosto de 2010 


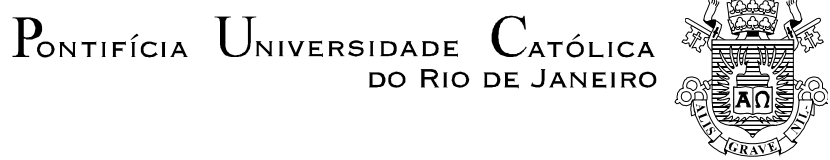

Tanya Linda Rothgiesser

Cidadania Digital: uma proposta de educação complementar para a inclusão digital e o combate às desigualdades sociais no Brasil contemporâneo - 0 caso CDI

Dissertação apresentada como requisito parcial para obtenção do grau de Mestre pelo Programa de Pós-graduação em Ciências Sociais da PUCRio. Aprovada pela Comissão Examinadora abaixo assinada.

Prof. Eduardo de Vasconcelos Raposo

Orientador

Departamento de Sociologia e Política - PUC-Rio

Prof. Bernardo Sorj ludcovsky IFCS/UFRJ

Profa. Angela Maria de Randolpho Paiva

Departamento de Sociologia e Política - PUC-Rio

Profa. Mônica Herz Coordenadora Setorial do Centro de Ciências Sociais - PUC-Rio

Rio de Janeiro, 31 de agosto de 2010 
Todos os direitos reservados. É proibida a reprodução total ou parcial do trabalho sem autorização da universidade, da autora e do Orientador.

\section{Tanya Linda Rothgiesser}

Graduou-se em Administração de Empresas pela Universidade Cândido Mendes-Praça XV, Rio de Janeiro. Fez pós-graduação em Psicanálise Lacaniana no Corpo Freudiano do Rio de Janeiro - Escola de Psicanálise. Gerenciou projetos sociais junto a organizações públicas, privadas e de Terceiro Setor. Coordenou no Instituto Nacional de Câncer (MS), por cinco anos, as Associações de Voluntariado vinculadas a quatro hospitais. Atua como pesquisadora e professora nas áreas de "Organização e Gestão do Trabalho Voluntário"; "Responsabilidade Social Corporativa" e "Responsabilidade Social Universitária".

Ficha Catalográfica

Rothgiesser, Tanya Linda

Cidadania digital : uma proposta de educação complementar para a inclusão digital e o combate às desigualdade sociais no Brasil contemporâneo - o caso CDI / Tanya Linda Rothgiesser ; orientador: Eduardo de Vasconcelos Raposo. - 2010.

200 f. : il. (color); $30 \mathrm{~cm}$

Dissertação (mestrado)-Pontifícia Universidade Católica do Rio de Janeiro, Departamento de Sociologia e Política, 2010.

Inclui bibliografia

1. Sociologia - Teses. 2. Inclusão digital. 3. Cidadania. 4. Cidadania digital. 5. Desigualdades Brasil. 6. CDI. I. Raposo, Eduardo de Vasconcelos. II. Pontifícia Universidade Católica do Rio de Janeiro. Departamento de Sociologia e Política. III. Título. 


\section{Agradecimentos}

Aos professores do Programa de Pós-graduação em Ciências Sociais da PUC-Rio, em especial ao meu orientador Professor Eduardo Raposo, pelos ensinamentos e apoio à realização deste trabalho.

Às funcionárias do Departamento de Sociologia e Política da PUC-Rio, pela paciência e carinho em todas as horas.

Aos colegas de turma, pela constante troca de conhecimentos e a alegria do convívio.

Aos colaboradores do CDI-Comitê para a Democratização da Informática e Instituições parceiras, pela confiança e generosidade em compartilhar suas experiências de vida e trabalho.

A Leandro Rothgiesser e Bruno Rothgiesser, pelo incentivo em todas as fases do processo e como referência de disciplina e dedicação aos estudos e à pesquisa. 


\section{Resumo}

Rothgiesser, Tanya Linda. Cidadania Digital: uma proposta de educação complementar para a inclusão digital e o combate às desigualdades sociais no Brasil contemporâneo - o caso CDI. Rio de Janeiro, 2010. 200 p. Dissertação de Mestrado - Departamento de Sociologia e Política, Pontifícia Universidade Católica do Rio de Janeiro.

'CIDADANIA DIGITAL': palavras de amplo entendimento quando separadas. Se vinculadas, problematizam a abordagem sociológica da expressão de um tempo. E remetem à busca, nos últimos decênios, de uma proposta de resultados à questão crucial das desigualdades sociais, entre as quais situa-se, com relevância, a da exclusão digital. Frente aos novos desafios das sociedades informacionais, a organização não governamental CDI-Comitê para a Democratização da Informática introduz, em 1995, uma proposta político pedagógica para a inclusão digital que, inspirada no educador Paulo Freire, articula conteúdos de informática e cidadania. Tem por objetivo, "transformar vidas" e, desta forma, promover a inclusão social. A presente pesquisa busca os resultados qualitativos desta proposta de educação complementar para o combate às desigualdades sociais em nosso país. Com este foco, concentramos os levantamentos em quatro instituições sem fins lucrativos, parceiras do CDI, na cidade do Rio de Janeiro. Ao longo de quatro meses foram entrevistados coordenadores, educadores, educandos e voluntários de Escolas "CDI Comunidade" e "EIC-Escola de Informática e Cidadania", tendo sido seus depoimentos contrastados com as propostas da Organização. Os resultados da pesquisa nos revelam que a articulação metodológica 'Informática e Cidadania' - por nós entendida como um processo de promoção da 'Cidadania Digital' - tem propiciado novas possibilidades de enfrentamento da info-exclusão no Brasil e contribuído, desta forma, para o combate às desigualdades sociais no Brasil contemporâneo.

\section{Palavras-chave}

Cidadania; inclusão digital; cidadania digital; desigualdades; Brasil; CDI. 


\section{Abstract}

Rothgiesser, Tanya Linda. Digital Citizenship: a complementary educational proposition to promote the digital inclusion and the fight against social inequalities in contemporary Brazil - the CDI case. Rio de Janeiro, 2010. 200 p. MSc. Dissertation - Departamento de Sociologia e Política, Pontifícia Universidade Católica do Rio de Janeiro.

'DIGITAL CITIZENSHIP': each of the two words individually has a widely known meaning. Joined as a phrase, they define the sociological approach of expression of our age. They relate to decades of search for solutions to critical issues derived from the social inequalities, one of which is digital exclusion. In 1995 the Brazilian non-governmental organization CDI (Information Technology Democratization Committee) introduces a politic-pedagogic project to articulate citizenship and information technology. Inspired by the Brazilian educator Paulo Freire, the CDI aims to "transform lives" to promote digital inclusion. Here we present an analysis on the qualitative results of that project on the fight against social inequalities in Brazil. The focus of the work is on four non-profit organizations that are partners of the CDI and are based in Rio de Janeiro. The four organizations give training courses on information and communication technologies to low-income communities with a program that the CDI elaborated. During four months we interviewed coordinators, educators, students and volunteers from these organizations. Their testimonials were collected and compared to the CDI's goals. The results indicate that the methodological articulation between "Citizenship and Information Technology" has enabled new possibilities for the fight against digital exclusion and the social inequalities in Brazil.

\section{Keywords}

Citizenship; digital inclusion; digital citizenship; inequalities; Brazil; CDI. 


\section{Sumário}

1. Apresentação 10

2. Conhecimento Tecnológico e Informação:

a Era da Sociedade Informacional

2.1. Introdução 15

2.2. Sociedade Informacional: a emergência de uma nova era 18

2.3. Informacionalismo: a nova cara do capítalismo 21

2.4. Sociedade em rede 23

2.5. Internet : seu nascimento em uma encruzilhada insólita 26

2.6. Internet : onde as culturas se encontram 29

2.7. Internet : novas formas de sociabilidade 33

2.8. Internet : participação política e cidadania em rede 36

2.9. Internet : os desafios $\quad 40$

2.10. Info-exclusão: a desigualdade informacional no Brasil 53

2.11. Conclusão 56

3. Cidadania no Brasil e Emergência das ONGs

3.1. Introdução 61

3.2. Cidadania brasileira: uma pirâmide de cabeça para baixo 67

3.3. De 'AMP' à 'ONG': em busca da construção de uma identidade 71

3.4. Rio ECO-92: "nada será como antes" 78

3.5. Responsabilidade Social Empresarial: doutrina e negócios 84

3.6. Conclusão 88 
4. Inclusão Digital e Cidadania: o estudo do caso CDI

4.1. Introdução 93

4.2. CDI: Histórico 99

4.3. CDI: Metodologia 109

4.4. CDI: Resultados 113

4.5. Escolas CDI: Inclusão Digital 116

4.6. Escolas CDI: Cidadania 141

4.7. Escolas CDI: Desigualdades 160

4.8. Conclusão 174

5. Conclusões Gerais 189

6. Referências bibliográficas 198 


\section{Lista de figuras}

Figura 1 - Capa da "Revista Veja", 1995:

"INTERNET - A rede planetária em que você ainda vai se plugar"

Figura 2 - Quadro da inflo-exclusão nos continentes, 2000-2009:

Figura 3 - Gráfico dos fluxos das informações pelo planeta, 2010: 